\title{
Early-auditory intervention in children with hearing loss and neurodevelopmental outcomes: cognitive, motor and language development
}

\author{
Pelin Çelik ${ }^{1 \oplus}$, Kemal Keseroğlu ${ }^{2 \odot}$, Serap Er ${ }^{3 \oplus}$, İclal Ayrancı Sucaklı1®, \\ Güleser Saylam ${ }^{2 \oplus}$, Halil İbrahim Yakut ${ }^{4 \oplus}$ \\ ${ }^{1}$ Department of Pediatrics, Division of Developmental and Behavioral Pediatrics, ${ }^{4}$ Department of Pediatrics, Ankara City Hospital, \\ Ankara; ${ }^{2}$ Department of Otorhinolaryngology, Head and Neck Surgery, Dışkapı Yıldırım Beyazıt Training and Research Hospital, \\ University of Health Sciences Turkey, Ankara; ${ }^{3}$ Department of Otorhinolaryngology, Head and Neck Surgery, Hearing-Speech-Balance \\ Unit, Dışkapı Yıldırım Beyazıt Training and Research Hospital, University of Health Sciences Turkey, Ankara, Turkey.
}

\begin{abstract}
Background. To date, studies have mostly focused on the language outcome of early-auditory interventions including amplification for congenital hearing loss within the first 6 months. We aimed to examine the effect of early-auditory intervention in patients with congenital hearing loss on cognitive, motor and language outcomes, and determine the clinical variables that affect developmental outcomes.
\end{abstract}

Methods. The medical records of 104 patients were retrospectively reviewed. Children were evaluated by the Bayley Scales of Infant and Toddler Development, Third Edition.

Results. The median ages of confirmation of hearing loss, amplification, starting auditory-verbal intervention and cochlear implantation were 9, 10, 13 and 19 months, respectively. Of the patients, 26\% received a hearingaid fitting $\leq 6$ months of age. Fifty-one children (49\%) had additional disabilities. The median cognitive, language and motor scores of children with no additional disabilities were 95 (65-115), 68 (47-103) and 97 (58$130)$, respectively and children with early-auditory intervention ( $\leq 6$ months) demonstrated higher cognitive, receptive and expressive language subscale scores than late-auditory intervention group $(\mathrm{p}<0.05)$ whereas there was no significant difference in motor scores $(p>0.05)$. A significant negative correlation was found between additional disability and cognitive, language and motor outcomes ( $r=-0.78, \mathrm{r}=-0.54$ and $\mathrm{r}=-0.75$, respectively $\mathrm{p}<0.01$ ). There was a significant negative correlation between language outcomes and the degree of hearing loss $(\mathrm{r}=-0.20$, $\mathrm{p}<0.05)$. Multiple regression analyses revealed that additional disability and early-auditory intervention showed a significant amount of variance in cognitive and language scores. The early intervention did not make a significant, independent contribution on motor outcomes whereas additional disability did.

Conclusions. Presence of additional disability was the strongest significant variable on developmental outcomes in hearing-impaired children. In children with no additional disability, significantly better cognitive and language scores were associated with the early-auditory intervention. Motor skills were not affected by the early-auditory intervention.

Key words: congenital hearing loss, early-auditory intervention, cognitive outcome, language outcome, motor outcome.

More than 250 million children (43\%) under 5 years of age living in low- and middle-income countries are at risk of not reaching their optimal

Pelin Çelik

drpelincelik06@gmail.com

Received 20th July 2020, accepted 14th December 2020. neurodevelopment. ${ }^{1}$ The first years of life are critically important for cognitive, linguistic, social, emotional and motor development. ${ }^{2}$ During this period, congenital hearing loss has a negative impact on development. The Joint Committee on Infant Hearing (JCIH) recommends that children should be screened for hearing loss by 1 month, diagnosed by 3 
months and should be received appropriate intervention by 6 months of age to reduce the negative effects of hearing loss on optimal development. ${ }^{3}$ These recommendations are also named as the Early Hearing Detection and Intervention (EHDI) guidelines. The age of amplification and early intervention commencement is decreasing due to newborn hearing screening programs (NHS) soon after birth.

Congenital hearing loss affects speech and language development negatively. ${ }^{4-6}$ Studies showed that children who were diagnosed and accessed auditory stimulation through hearing aids within the first six months of life, have significantly better language acquisition. ${ }^{7,8}$ Although, the impact of auditory deprivation on language development has been extensively studied, comparably less research has been focused on the effect of hearing loss on nonverbal skills including cognitive and motor development. ${ }^{9} \quad$ As speech and language development are prerequisites for cognitive development, an auditory defect may have a negative effect on the hearing-impaired child's cognitive ability. ${ }^{10-12}$ Some studies showed that hearing impairment was associated with impaired motor development especially gross motor skills ${ }^{13-15}$ whereas some authors reported motor scores of hearing impaired children to be within typical ranges. ${ }^{16,17}$

The primary purpose of thisstudy was toevaluate the effects of the early auditory intervention (fitting of amplification) on cognitive and motor outcomes as well as language outcomes. The secondary purpose was to determine clinical and sociodemographic variables that influence the language, cognitive and motor outcomes in children with congenital hearing loss.

\section{Material and Methods}

\section{Procedure and Participants}

This retrospective study was conducted at the Department of Developmental and Behavioral Pediatrics, Ankara Child Health and Diseases Hematology and Oncology Training and Research Hospital, University of Health Sciences Turkey, and Department of Otorhinolaryngology, Head and Neck Surgery of Dışkapı Yıldırım Beyazit Training and Research Hospital, University of Health Sciences Turkey. Participants were children with congenital hearing loss ranging from mild to profound who were followed by both departments between January 2018 and June 2019.

This retrospective research was reviewed and approved by the Ethical Committee of Ankara City Hospital, Turkey (24.12.2019-E1/235/2019) and also reviewed and approved by the institutional review board of Ankara Child Health and Diseases Hematology and Oncology Training and Research Hospital, University of Health Sciences Turkey (18.07.2019/17). Informed consent was not taken because of retrospective design of the study.

Inclusion criteria were: 1) bilateral, congenital sensorineural hearing loss ranging from mild to profound requiring amplification 2) living in a Turkish-speaking home 3) chronological age between 8-42 months 4) children without auditory neuropathy.

Clinical records were retrospectively reviewed. Sociodemographic data, presence or absence of additional disability, gender, age at diagnosis, degree of hearing loss, age at amplification or cochlear implantation, age of enrollment for auditory-verbal therapy, communication mode used by the family, parental education status, household income, parental consanguinity, the hearing status of the family members were extracted from clinical charts.

\section{Additional Disability}

Additional disability was defined as cerebral palsy, visual impairment, autism spectrum disorder, extreme prematurity, genetic, metabolic or neurological diseases or other medical conditions that may affect cognitive, language or motor outcomes. 


\section{Degree of Hearing Loss}

The degree of hearing loss was determined by using the better-ear pure tone average which was calculated for the thresholds at $500 \mathrm{~Hz}$, $1 \mathrm{kHz}$, and $2 \mathrm{kHz}$. It was classified according to American Speech-Language-Hearing Association. ${ }^{18}$

\section{Auditory Intervention}

The early-auditory intervention was described as diagnosis of hearing loss and fitting of a hearing aid by 6 months of age, and lateauditory intervention was described as fitting of a hearing aids $>6$ months age or not fitted yet. All patients received auditory-verbal therapy which was provided by the government health insurance as 2 hours per week.

\section{Developmental Assessment}

Cognitive, language and motor function were evaluated by the Bayley Scales of Infant and Toddler Development, Third Edition (BayleyIII). ${ }^{19}$ This was designed to measure the child's level of development in three scales; cognitive, language and motor (expected population mean 100; standard deviation (SD) 15). The language scale is composed of receptive communication and expressive communication subscales. The motor scale is composed of fine and gross motor subscales (mean 10, SD 3). During the assessment, it was made sure that the child used the hearing aid or cochlear implant correctly; ambient noise was minimized and the child was spoken to clearly and naturally with a parent present.

\section{Statistical Analysis}

Statistical analyses were performed using the SPSS statistical package (v. 20.0 for MAC). Categorical variables between groups were analyzed using the $\chi 2$ test. Comparison of means between two groups was examined using a t-test, where the data fit a normal distribution. For comparison of more than two groups, ANOVA was used for normal distributions and the Kruskal-Wallis test for nonnormal distributions. A p-value of $<0.05$ was deemed to indicate statistical significance. To explore the relationships Spearman's correlation test was performed. Multiple regression analysis was used to investigate the effect of predictor variables on outcomes, after controlling for the effects of other variables.

\section{Results}

One hundred and four children were enrolled in the study. The median age was $25.5(8-42)$ months. Of the children, $79.8 \%$ were diagnosed as a result of the NHS. The median ages of confirmation of hearing loss, amplification, auditory-verbal therapy and cochlear implantation were 9 (0- 42), 10 (3-36), 13 (3-35) and 19 (12-40) months, respectively.

Sociodemographic and clinical characteristics are presented in Table I. Moderately severe to profound hearing loss was observed in 85 (81.7\%) children. While 27 (26\%) children were identified and instrumented with hearing aids by $0-6$ months of age, 56 (53.8\%) children fitted their first hearing aid after 6 months of age. Only $9(8.6 \%)$ children met all 3 components of the EHDI guidelines. Twenty-one (20.2\%) children had unmet needs in terms of amplification. Of children with hearing aids $53.7 \%$ and of children with cochlear implants $76 \%$ were wearing the device all waking hours without resistance.

The median Bayley-III cognitive, language and motor scores of the study group were 85 (55-115), 59 (47-103) and 82 (46-130) respectively. Fiftyone of the 104 children (49\%) had one or more additional disability other than their hearing loss including visual impairment, autism spectrum disorder, neurological, metabolic or genetic diseases (Table II). Of children with an additional disability $68.7 \%$ were fitted with a hearing aid or cochlear implant, and $82 \%$ of them were fitted $>6$ months of age.

When considering the 53 children with no additional disability, the median cognitive, language and motor scores were 95 (65-115), 68 (47-103), 97 (58-130) respectively. Table III 
Table I. Sociodemographic and clinical characteristics.

\begin{tabular}{|c|c|}
\hline Characteristics & $\mathrm{n}(\%)$ \\
\hline \multicolumn{2}{|l|}{ Gender } \\
\hline Male & $64(61.5)$ \\
\hline Female & $40(38.5)$ \\
\hline \multicolumn{2}{|l|}{ Degree of hearing loss } \\
\hline Mild (26-40 dB HL ) & $2(1.9)$ \\
\hline Moderate (41-55 dB HL ) & $13(12.5)$ \\
\hline Moderately severe (56-70 dB HL ) & $22(21.2)$ \\
\hline Severe (71-90 dB HL ) & $19(18.2)$ \\
\hline Profound (>90 dB HL ) & $44(42.3)$ \\
\hline Unknown (not reported) & $4(3.8)$ \\
\hline \multicolumn{2}{|l|}{ Universal newborn hearing screening } \\
\hline Passed & $11(10.6)$ \\
\hline Failed & $83(79.8)$ \\
\hline Not screened & $2(1.9)$ \\
\hline Unknown (family does not remember) & $8(7.7)$ \\
\hline \multicolumn{2}{|l|}{ Age of onset of hearing loss } \\
\hline Congenital & $93(89.4)$ \\
\hline Late onset (before 2 years) & $11(10.6)$ \\
\hline \multicolumn{2}{|l|}{ Type of amplification } \\
\hline None & $21(20.2)$ \\
\hline Hearing aids & $57(54.8)$ \\
\hline Cochlear implant & $1(1)$ \\
\hline Cochlear implant after hearing aid & $25(24)$ \\
\hline \multicolumn{2}{|l|}{ Identified and intervention of hearing loss } \\
\hline Early (diagnosed and instrumented with hearing aids by 6 months of age) & $27(26)$ \\
\hline Late (instrumented $>6$ months of age or not instrumented) & $77(74)$ \\
\hline \multicolumn{2}{|l|}{ Communication mode used with the child } \\
\hline Spoken language only & $60(57.6)$ \\
\hline Spoken language with occasional use of sign language & $26(25)$ \\
\hline Sign language only & $5(4.8)$ \\
\hline Unable to communicate because of severe neurologic impairment & $13(12.5)$ \\
\hline \multicolumn{2}{|l|}{ Language at home } \\
\hline Monolingual (Turkish) & $82(78.9)$ \\
\hline Bilingual & $22(21.1)$ \\
\hline \multicolumn{2}{|l|}{ Consanguinity } \\
\hline Consanguineous marriages & $51(49)$ \\
\hline First degree cousin marriage & $22(21.2)$ \\
\hline Second degree cousin marriage & $14(13.5)$ \\
\hline Third degree cousin marriage & $2(1.9)$ \\
\hline Same village & $13(12.5)$ \\
\hline No consanguinity & $53(50.9)$ \\
\hline
\end{tabular}


Table I. Continued.

\begin{tabular}{lc}
\hline Characteristics & $\mathrm{n}(\%)$ \\
\hline Hearing status of the family members & \\
$\quad$ One or both parents or siblings deaf & $23(22.1)$ \\
Deafness and/or hard of hearing in any other family members & $19(18.3)$ \\
$\quad$ Parents, siblings and other family members hearing & $62(59.6)$ \\
Mother's education & \\
$\quad \leq 12$ years & $95(91.3)$ \\
$>12$ years & $9(8.7)$ \\
Father's education & \\
$\leq 12$ years & $85(81.7)$ \\
$>12$ years & $19(18.3)$ \\
Annual income (USD) & \\
$\quad$ No reguler income & $21(20.2)$ \\
$<3000$ USD & $37(35.6)$ \\
$3001-5000$ USD & $23(22.1)$ \\
$5001-8000$ USD & $12(11.5)$ \\
$\geq 8001$ USD & $11(10.5)$ \\
\hline
\end{tabular}

Table II. Additional disability.

\begin{tabular}{lc}
\hline Additional disability (n: 51)* & $\mathrm{n}(\%)$ \\
\hline Cerebral palsy & $24(23.1)$ \\
Seizures & $18(17.3)$ \\
Cleft palate & $1(1)$ \\
Metabolic disesases (Mucopolysaccharidosis type 1, Mucopolysaccharidosis type 2, Tay-Sachs, & $5(5)$ \\
mannosidosis, fatty acid oxidation defect) & \\
Genetic syndromes (Down syndrome, Pendred syndrome, Beckwith-Wiedemann syndrome, & $13(12.5)$ \\
Waardenburg syndrome, Cornelia de Lange syndrome, Pierre Robin sequence, 1p36 duplication & \\
syndrome, Kleefstra syndrome, CHARGE syndrome, Holt-Oram syndrome) & \\
Visual impairment & $32(30.7)$ \\
Autism spectrum disorder & $5(4.8)$ \\
Other & $4(3.8)$ \\
\hline
\end{tabular}

*Some children had more than 1 additional disability

illustrates the Bayley-III scores of the children with no additional disability according to the early or late-auditory intervention. In the earlyauditory intervention group, cognitive and language scores were significantly higher than the late intervention group ( $\mathrm{p}<0.01$ ), whereas there was no significant difference in motor scores. Comparison of Bayley-III language subscaled scores showed that both receptive and expressive communication scaled scores were significantly higher in the early intervention group $(\mathrm{p}<0.01)$.
Table IV provides the Spearman's rho correlations between the Bayley-III language, cognitive and motor scores and the independent variables: gender, age, presence of additional disability, the early-auditory intervention, degree of hearing loss, hearing loss in firstdegree family members, mother's education $>8$ years, and household income. Of the variables examined, the strongest significant correlation was obtained between additional disability and Bayley-III cognitive, language and motor scores $(r=-0.78, r=-0.54$ and $r=-0.75$, respectively 
Table III. Bayley-III scores of the children with no additional disability according to identification and intervention age.

\begin{tabular}{|c|c|c|c|c|}
\hline \multirow[t]{3}{*}{ Bayley-III scores } & \multirow{3}{*}{$\begin{array}{l}\text { Early intervention } \\
\text { Group }^{\mathrm{a}} \\
(\mathrm{n}=21)\end{array}$} & \multicolumn{2}{|c|}{ Late intervention Total ${ }^{a}$} & \multirow[t]{3}{*}{ p-value } \\
\hline & & Group $^{a}$ & $(n=53)$ & \\
\hline & & $(n=32)$ & & \\
\hline Cognitive composite score & $100(90-115)$ & $92(65-115)$ & $95(65-115)$ & 0.000 \\
\hline Language composite score & $86(50-103)$ & $63.5(47-91)$ & $68(47-103)$ & 0.002 \\
\hline Motor composite score & $100(73-112)$ & $94(58-130)$ & $97(58-130)$ & 0.068 \\
\hline Cognitive scaled score & $10(8-13)$ & $8.5(3-13)$ & $9(3-13)$ & 0.000 \\
\hline Receptive communication scaled score & $6(1-10)$ & $3(1-9)$ & $4(1-10)$ & 0.007 \\
\hline Expressive communication scaled score & $8(3-11)$ & $5(1-9)$ & $6(1-11)$ & 0.000 \\
\hline Fine motor scaled score & $10(6-14)$ & $10(2-15)$ & $10(2-15)$ & 0.230 \\
\hline Gross motor scaled score & $9(1-15)$ & $8(1-15)$ & $9(1-15)$ & 0.075 \\
\hline
\end{tabular}

aedian values and minimum-maximum values are presented

Table IV. Correlations between the Bayley-III language, cognitive and motor scores and independent variables.

\begin{tabular}{llllllllllll}
\hline & $\begin{array}{l}\text { Cognitive } \\
\text { composite }\end{array}$ & $\begin{array}{l}\text { Language } \\
\text { scomposite }\end{array}$ & $\begin{array}{l}\text { Motor } \\
\text { scomposite }\end{array}$ & 1 & 2 & 3 & 4 & 5 & 6 & 7 & 8 \\
& score & score & & & & & & & \\
\hline 1. Gender & 0.08 & 0.00 & 0.09 & - & - & - & - & - & - & - & - \\
2. Age & -0.15 & -0.01 & 0.08 & 0.00 & - & - & - & - & - & - & - \\
3. Additional disability & $-0.78^{* *}$ & $-0.54^{* *}$ & $-0.75^{* *}$ & -0.13 & 0.04 & - & - & - & - & - & - \\
4. Early auditory & $0.44^{* *}$ & $0.39^{* *}$ & $0.35^{* *}$ & -0.02 & $-0.20^{*}-0.31^{* *}-$ & - & - & - & - \\
intervention & & & & & & & & & & & \\
5. Degree of hearing loss & 0.05 & $-0.20^{*}$ & -0.00 & -0.15 & $-0.20^{*}-0.05$ & 0.06 & - & - & - & - \\
6. Hearing loss in first & 0.14 & 0.05 & 0.16 & -0.19 & 0.04 & $-0.26^{*}$ & 0.02 & 0.10 & - & - & - \\
degree family member & & & & & & & & & & & \\
7. Mother's education & -0.02 & -0.01 & -0.05 & 0.00 & -0.06 & 0.00 & 0.07 & 0.00 & -0.07 & - & - \\
8. Income & -0.01 & 0.11 & -0.07 & -0.09 & -0.04 & 0.15 & 0.00 & -0.01 & $-0.29^{*}$ & $0.31^{*}$ & - \\
\hline
\end{tabular}

Degree of hearing loss: mild to moderate versus moderately severe to profound

Mother's level of education: $\leq 12$ years versus $>12$ years

${ }^{*} \mathrm{p}<0.05,2$-tailed.

${ }^{* *} \mathrm{p}<0.01,2$-tailed.

$\mathrm{p}<0.01)$. Cognitive, language and motor scores were found to be significantly increased with the early-auditory intervention (cognitive; $\mathrm{r}=0.44$, language; $\mathrm{r}=0.39$, and motor; $\mathrm{r}=0.35$, $\mathrm{p}<0.01)$. A significant negative correlation was found between language outcomes and degree of hearing loss $(\mathrm{r}=-0.20, \mathrm{p}<0.05)$. But there was no association between cognitive, language and motor outcomes and other demografic variables. The interaction between age at amplification and presence/absence of additional disability was significant $(\mathrm{r}=-0.31, \mathrm{p}<0.01)$. There was also a correlation between income and mothers' education $(\mathrm{r}=0.31, \mathrm{p}<0.05)$.
Multiple regression analyses were conducted for further exploration of the relationships between age, sex, additional disability, earlyauditory intervention, degree of hearing loss, hearing loss in first degree family members, mother's education, household income and cognitive, language and motor scores (Table V). The presence of additional disability made the strongest significant contribution on cognitive, language and motor outcomes. The early-auditory intervention also made a significant, independent contribution to both the cognitive and language outcomes. Higher cognitive and language scores were predicted 
Table V. Multiple Regression Models for predicting cognitive, language and motor composite scores.

\begin{tabular}{|c|c|c|c|c|c|c|c|c|}
\hline & $\mathrm{R}^{2}$ & F & $\mathrm{p}$ & & $\begin{array}{l}\text { Unstandardized } \\
\text { coefficient }\end{array}$ & $\begin{array}{l}\text { Standardized } \\
\text { coefficient }\end{array}$ & $\begin{array}{l}\mathrm{t} \text { test } \\
\text { value }\end{array}$ & $\mathrm{p}$ \\
\hline \multirow{4}{*}{$\begin{array}{l}\text { Cognitive } \\
\text { composite } \\
\text { score }\end{array}$} & \multirow{4}{*}{0.633} & \multirow{4}{*}{31.44} & \multirow{4}{*}{$<0.0001$} & Additional disability & -25.49 & -0.69 & -9.09 & $<0.0001$ \\
\hline & & & & Early auditory intervention & 8.79 & 0.21 & 2.88 & $<0.01$ \\
\hline & & & & Household income & 1.89 & 0.12 & 1.62 & 0.109 \\
\hline & & & & Mother's education & 10.03 & 0.14 & 1.86 & 0.067 \\
\hline \multirow{6}{*}{$\begin{array}{l}\text { Language } \\
\text { composite } \\
\text { score }\end{array}$} & \multirow{6}{*}{0.443} & \multirow{6}{*}{9.27} & \multirow{6}{*}{$<0.0001$} & Gender & -4.15 & -0.12 & -1.33 & 0.187 \\
\hline & & & & Additional disability & -12.77 & -0.39 & -4.08 & $<0.0001$ \\
\hline & & & & Early auditory intervention & 10.54 & 0.29 & 3.12 & $<0.01$ \\
\hline & & & & Degree of hearing loss & -14.56 & -0.31 & -3.49 & $<0.01$ \\
\hline & & & & Household income & 3.14 & 0.23 & 2.41 & 0.018 \\
\hline & & & & Mother's education & 9.61 & 0.15 & 1.61 & 0.110 \\
\hline \multirow{4}{*}{$\begin{array}{l}\text { Motor } \\
\text { composite } \\
\text { score }\end{array}$} & \multirow{4}{*}{0.606} & \multirow{4}{*}{26.64} & \multirow{4}{*}{$<0.0001$} & Age & 0.40 & 0.17 & 2.18 & 0.032 \\
\hline & & & & Additional disability & -32.75 & -0.69 & -8.62 & $<0.0001$ \\
\hline & & & & Early auditory intervention & 7.98 & 0.15 & 1.92 & 0.058 \\
\hline & & & & Mother's education & -11.88 & 0.13 & 1.78 & 0.079 \\
\hline
\end{tabular}

by the early-auditory intervention. But the early-auditory intervention did not make a significant, independent contribution to the motor outcomes. Lower language scores were predicted by the higher degree of hearing loss and lower levels of household income. Motor scores also increased as chronological age increased.

\section{Discussion}

This study, which examined the effect of early-auditory intervention on developmental outcomes in children with congenital hearing loss revealed that early-auditory intervention was associated with higher Bayley-III cognitive and language scores, but not motor scores. The presence of additional disability was also found to be the strongest significant variable on all developmental domains in hearing-impaired children.

Despite the benefits of early-auditory intervention, the median language score of children with no additional disability and early-auditory intervention was $86(<1$ SD of the expected mean of 100) in our study. YoshinagaItano et al. ${ }^{8}$ and Ching et al. ${ }^{20}$ similary showed that hearing impaired children who were detected early and treated with amplification had language scores at or below 1 SD of the normative mean. Although our study was one of the rare studies ${ }^{21}$ evaluating the language skills of children with hearing loss with Bayley-III, the language score was similar to other studies using different language assessment tools including MacArtur-Bates Communicative Development Inventories, Preschool Language Scale v.4, Child Development Inventory, Peabody Picture vocabulary test. ${ }^{8,20}$ Multiple regression analysis showed that early auditory intervention, absence of additional disability, a lesser degree of hearing loss and a higher level of household income were associated with better language scores in the current study, consistent with previous studies. $5,8,20,22$

To date, few studies have investigated the cognitive skills of hearing impaired toddlers and young children. ${ }^{11}$ Kutz et al. ${ }^{11}$ revealed the overall poor performance of cognitive skills in a small number of hearing-impaired toddlers and young children. However, most research was conducted in school-aged children ${ }^{23,24}$ and adolescents. ${ }^{25,26}$ Martinez-Cruz et al. ${ }^{23}$ showed that children with unilateral severe to profound sensorineural hearing loss had significantly lower intelligence coefficients 
than healthy children. Emmett et al. ${ }^{26}$ reported that hearing loss in adolescents and young adults would be associated with decreased nonverbal intelligence. Academic achievement of children with severe to profound hearing loss was significantly impaired relative to peers. ${ }^{24}$ Teasdale et al. ${ }^{25}$ found that mean intelligence quotients (IQ) of adolescents with normal hearing, mild hearing loss and more severe hearing loss were 101, 98 and 94, respectively. In our study, the median cognitive score of toddlers without an additional disability was 95 in consistent with Teasdale's study. It is important to note that our study was performed at a younger age and the measurement derives a developmental quotient (DQ), not IQ. Additionally, the median cognitive score of children with early diagnosis and fitting hearing aid completed by 6 months of age was 100 , within the normative population and statistically significantly higher than the late intervention group. Because of impaired auditory functions in the prelingual period, the nervous system can not get enough information and input, which may affect cognitive development. Hearing impaired children obtain sound, enrich their knowledge, boost their confidence by early-auditory intervention and, cognitive development is promoted. Therefore, the earlier the diagnosis is made and the intervention is started, the better the intelligence development gets.

Motor outcomes have received less attention in the literature for hearing impaired children. A systematic review reported that these children had difficulties especially in balance function. ${ }^{27}$ Schlumberger et al. ${ }^{12}$ found that hearing impaired children without neurologic diseases had reduced balance and complex motor movements. In contrast, Leigh et al. ${ }^{16}$ showed that fine and gross motor development scores were within the typical range for healthy children. In our study, median fine and gross motor scaled scores of children without additional disabilities were 10 (2-15) and 9 (115) respectively and, within normal limits. Several studies have investigated the effect of the early-auditory intervention on motor skills, but the results were controversial. Sahli et al. ${ }^{28}$ showed that children who received an early diagnosis and intervention in accordance with EHDI Guidelines had significantly better fine and gross motor skills. Korver et al. ${ }^{17}$ reported better gross motor subscales but similar fine motor subscales in early-identified children when comparing with the late-identified group. In contrast, Leigh et al. ${ }^{16}$ found that earlyauditory intervention was not significantly associated with motor outcomes. In conjunction with the study of Leigh et al., ${ }^{16}$ early-auditory intervention was not found to be an independent factor affecting motor scores in our study. The average age of children at the time of testing in our study was similar to studies of Sahli et al. ${ }^{28}$ and Leigh et al., ${ }^{16}$ but younger than the study of Korver et al. ${ }^{17}$ Also, we used BayleyIII for developmental assesment whereas other studies used the Child Development Inventory or the Denver Development Screening Test-II. The different results may be associated with different age groups and assessment tools used. Surprisingly it was found that motor scores were increased as chronological age increased. Kegel et al. ${ }^{29}$ showed a decrease in gross motor scores in hearing-impaired children within the age period of implantation, and increased motor skills at the age of 2 years in a prospective study. Our result may be related to the tendency to catch-up on motor skills over time as suggested by Kegel et al. ${ }^{29}$ But more follow up studies are needed to confirm whether the trajectory of gross motor development changes over time.

In the current study, children with additional disabilities were not excluded in order to determine the effect of the presence of an additional disability on developmental outcomes in hearing impaired children. Additional disability was found to be the strongest significant independent factor affecting cognitive, language and motor outcomes in the multiple regression analysis. It should be noted that amplification rate was lower and a hearing aid was fitted at an older age in hearing-impaired children with an additional 
disability in this study. Beer et al..$^{30}$ showed that children with additional disabilities can benefit from auditory intervention, albeit at a slower pace and/or lesser degree than children with no additional disabilities. So, clinicians should be aware of the importance of accessing early auditory intervention options such as a hearing aid or cochlear implantation in time to reach their developmental potential in hearing impaired children with an additional disability.

Studies in Australia and the United States have reported that $56-58 \%$ of children with congenital hearing loss have had their first hearing aid by 6 months of age. ${ }^{8,20}$ According to recent studies from different regions of Turkey, the rate of children being fitted with a hearing aid by 6 months was $18.9-26.4 \%{ }^{28,31}$ Similarly, our study showed that the rate of children who were diagnosed and fitted with hearing aids by 6 months of age was only $26 \%$. Also, it should be noted that $20.2 \%$ of children had unmet needs in terms of amplification in our study. This means that, although the NHS program has been successfully implemented in Turkey the next steps including fitting hearing aids and auditory-verbal interventions have not been conducted effectively. Transportation difficulties, the inability of the family to understand the importance of hearing loss on the child's development, exhaustion of the family during the diagnostic process, family's resistance to accept that their child has hearing loss and particularly being of low socioeconomic status may negatively affect children to reach early-auditory intervention.

The limitations of our study included the retrospective design of the study, the lack of a control group and long-term follow-up results. Also, the majority of children in our study had moderately severe to profound hearing loss and had additional disabilities, so the results are not generalizable to all children with hearing loss.

In conclusion, to the best of our knowledge, this is the first study exploring all developmental domains in hearing-impaired children. Fitting a hearing aid by 6 months of age in children with congenital hearing loss and no other concomitant disability provided similar cognitive and motor skills to their typically hearing peers but lower language skills. Early-auditory intervention was an independent predictor for language and cognitive scores but not motor scores. The presence of additional disability significantly influence all developmental domains in hearingimpaired children. Hearing-impaired children with additional disabilities tend to have no or late auditory intervention. Professionals should be aware of the importance of early detection and early intervention for hearing-impaired children with or without additional disabilities.

\section{Author contribution}

The authors confirm contribution to the paper as follows: study conception and design: Pelin Çelik, Kemal Keseroğlu, Halil İbrahim Yakut, Güleser Saylam; data collection: Pelin Çelik, Serap Er, İclal Ayrancı Sucakli; analysis and interpretation of results: Pelin Çelik, İclal Ayrancı Sucakli; draft manuscript preparation: Pelin Çelik, İclal Ayrancı Sucaklı. All authors reviewed the results and approved the final version of the manuscript.

\section{Ethical approval}

This retrospective research was reviewed and approved by the Ethical Committee of Ankara City Hospital, Turkey (24.12.2019-E1/235/2019) and also reviewed and approved by the institutional review board of Ankara Child Health and Diseases Hematology and Oncology Training and Research Hospital, University of Health Sciences Turkey (18.07.2019/17).

\section{Source of funding}

There is no funding source.

\section{Conflict of interest}

The authors declare that they have no conflict of interest. 


\section{REFERENCES}

1. Black MM, Walker SP, Fernald LCH, et al; Lancet Early Childhood Development Series Steering Committee. Early childhood development coming of age: science through the life course. Lancet 2017; 389: 77-90.

2. Shonkoff JP, Phillips DA; National Research Council (US) and Institute of Medicine (US) Committee on Integrating the Science of Early Childhood Development. From Neurons to Neighborhoods: The Science of Early Childhood Development. Washington DC: National Academies Press (US), 2000.

3. American Academy of Pediatrics, Joint Committee on Infant Hearing (JCIH). Year 2007 position statement: principles and guidelines for early hearing detection and intervention programs. Pediatrics 2007; 120: 898-921.

4. Nott P, Cowan R, Brown PM, Wigglesworth G. Early language development in children with profound hearing loss fitted with a device at a young age: part I--the time period taken to acquire first words and first word combinations. Ear Hear 2009; 30: 526-540.

5. Tomblin JB, Harrison M, Ambrose SE, Walker EA, Oleson JJ, Moeller MP. Language outcomes in young children with mild to severe hearing loss. Ear Hear 2015; 36(Suppl 1): S76-S91.

6. American Speech-Language-Hearing Association (ASHA). Effects of Hearing Loss on Development. Available at: www. asha. org/ public/ hearing/ effects- of- hearing- loss- ondevelopment. (Accessed on November 12, 2019)

7. Sininger YS, Grimes A, Christensen E. Auditory development in early amplified children: factors influencing auditory-based communication outcomes in children with hearing loss. Ear Hear 2010; 31: 166-185.

8. Yoshinaga-Itano C, Sedey AL, Wiggin M, Chung W. Early hearing detection and vocabulary of children with hearing loss. Pediatrics 2017; 140: e20162964.

9. Pierson SK, Caudle SE, Krull KR, Haymond J, Tonini R, Oghalai JS. Cognition in children with sensorineural hearing loss: etiologic considerations. Laryngoscope 2007; 117: 1661-1665.

10. Chapman RS. Children's language learning: an interactionist perspective. J Child Psychol Psychiatry 2000; 41: 33-54.
11. Kutz W, Wright C, Krull KR, Manolidis S. Neuropsychological testing in the screening for cochlear implant candidacy. Laryngoscope 2003; 113: 763-766.

12. Schlumberger E, Narbona J, Manrique M. Nonverbal development of children with deafness with and without cochlear implants. Dev Med Child Neurol 2004; 46: 599-606.

13. Nandi R, Luxon LM. Development and assessment of the vestibular system. Int J Audiol 2008; 47: 566577.

14. Kaga K, Shinjo Y, Jin Y, Takegoshi H. Vestibular failure in children with congenital deafness. Int J Audiol 2008; 47: 590-599.

15. Inoue A, Iwasaki S, Ushio M, et al. Effect of vestibular dysfunction on the development of gross motor function in children with profound hearing loss. Audiol Neurootol 2013; 18: 143-151.

16. Leigh G, Ching TY, Crowe K, Cupples L, Marnane $\mathrm{V}$, Seeto $\mathrm{M}$. Factors affecting psychosocial and motor development in 3-year-old children who are deaf or hard of hearing. J Deaf Stud Deaf Educ 2015; 20: 331342.

17. Korver AM, Konings S, Dekker FW, et al; DECIBEL Collaborative Study Group. Newborn hearing screening vs later hearing screening and developmental outcomes in children with permanent childhood hearing impairment. JAMA 2010; 304: 1701-1708.

18. ASHA-American Speech-Language-Hearing Association. Degree of Hearing Loss. Available at: https://www.asha.org/public/hearing/Degree-ofHearing-Loss/ (Accessed on October 26, 2019).

19. Bayley N. Bayley Scales of Infant and Toddler Development (Bayley-III). (3rd ed). San Antonia, TX, USA: PsychCorp, Pearson, Harcourt Assessment, 2006.

20. Ching TY, Dillon H, Marnane V, et al. Outcomes of early- and late-identified children at 3 years of age: findings from a prospective population-based study. Ear Hear 2013; 34: 535-552.

21. Bavin EL, Sarant J, Leigh G, Prendergast L, Busby $\mathrm{P}$, Peterson C. Children with cochlear implants in infancy: predictors of early vocabulary. Int J Lang Commun Disord 2018; 53: 788-798.

22. Geers AE, Nicholas JG, Sedey AL. Language skills of children with early cochlear implantation. Ear Hear 2003; 24(Suppl 1): S46-S58. 
23. Martinez-Cruz CF, Poblano A, Conde-Reyes MP. Cognitive performance of school children with unilateral sensorineural hearing loss. Arch Med Res 2009; 40: 374-379.

24. Sarant JZ, Harris DC, Bennet LA. Academic outcomes for school-aged children with severeprofound hearing loss and early unilateral and bilateral cochlear implants. J Speech Lang Hear Res 2015; 58: 1017-1032.

25. Teasdale TW, Sorensen MH. Hearing loss in relation to educational attainment and cognitive abilities: a population study. Int J Audiol 2007; 46: 172-175.

26. Emmett SD, Schmitz J, Pillion J, et al. Hearing loss is associated with decreased nonverbal intelligence in rural Nepal. Otol Neurotol 2015; 36: 86-92.

27. Vidranski T, Farkas D. Motor skills in hearing impaired children with or without cochlear implant-a systematic review. Coll Antropol 2015; 39(Suppl 1): 173-179.
28. Sahli AS. Developments of children with hearing loss according to the age of diagnosis, amplification, and training in the early childhood period. Eur Arch Otorhinolaryngol 2019; 276: 2457-2463.

29. De Kegel A, Maes L, Van Waelvelde H, Dhooge I. Examining the impact of cochlear implantation on the early gross motor development of children with a hearing loss. Ear Hear 2015; 36: e113-121.

30. Beer J, Harris MS, Kronenberger WG, Holt RF, Pisoni DB. Auditory skills, language development, and adaptive behavior of children with cochlear implants and additional disabilities. Int J Audiol 2012; 51: 491-498.

31. Konukseven O, Kaya S, Genc A, et al. Regional differences of Turkey in risk factors of newborn hearing loss. Int J Pediatr Otorhinolaryngol 2017; 102: 49-55. 